\title{
Force Measurement System for Roller-Ski Skating
}

\author{
Jurij HLADNIK, Matej SUPEJ, Boris JERMAN
}

\begin{abstract}
For a detailed biomechanical analysis of roller-ski skating a precise measurement of ground reaction forces is needed in addition to the measurement of the kinematic parameters. An innovative portable force measuring system was developed from processed roller-skis and ski poles equipped with strain gauges. The measuring system can measure normal (with respect to the upper surface of the roller-ski) and transverse forces (in the axial direction of the wheel) on each wheel, and axial forces in the ski poles. Force sensors are connected by cables to the data acquisition system carried in a backpack by the runner. In case of terrain usage, also a portable computer and a power supply are carried in the backpack. Calibration procedure for this measurement system is presented and measurement uncertainty of the sensors is calculated. The estimated measurement uncertainty of the entire measuring chain of individual roller-ski sensor, at a confidence level of $95 \%$, is up to $\pm 2,34 \%$ of the maximum calibration forces. For the sensors of the poles this value makes up to $\pm 1,47 \%$ of the maximum calibration force. Sample data from a roller-ski skating trial on a treadmill is presented and interpreted.
\end{abstract}

Keywords: cross-country skiing; force measurement system; kinetics; treadmill roller-skiing

\section{INTRODUCTION}

For a detailed understanding of the biomechanics of cross-country skiing, its kinematics and kinetics need to be known. There were several studies done in the past in which various measurement systems for recording reaction forces during cross-country skiing have been developed. Because roller-skiing is usually more appropriate for laboratory testing (treadmill running), studies of crosscountry skiing are often performed on roller-skis. Also for measuring the reaction forces roller-skis seem to be more advantageous.

There are three main methods for measuring the reaction forces in cross-country/roller skiing:

- with external tensiometric platforms,

- with pressure insoles inserted in the footwear or

- with cross-country skis/roller-skis and ski poles instrumented with force sensors.

The first method is relatively simple and provides reaction forces of the athlete in the coordinate system of the platforms, which is often advantageous. Its weakness is that the reaction forces can only be measured when skiing on the platforms, which requires many platforms (especially for the skating technique) and is either expensive or limited with space. This method was used inter alia in [1] using skate technique on roller-skis and in [2] using skate technique on cross-country skis.

The second method for measuring reaction forces in cross-country/roller skiing is, contrary to the external tensiometric platforms, considerably cheaper and spatially less limited. The pressure insoles consist of several small pressure sensors, which allow the calculation of the reaction forces' point of application on the sole and to view the pressure distribution on the sole. The disadvantages of the pressure insoles are that they measure just the normal forces and that the accuracy of the measured forces is questionable, because not all of the reaction force is transmitted through the pressure sensors. This method was used in cross-country skiing inter alia in [3], [4] and [5].

For longer-lasting measurements with higher accuracy needs cross-country skis/roller-skis and ski poles instrumented with force sensors are probably the most convenient. Unfortunately, there is no such commercially available measurement system, so unique realizations need to be done. So far, several such more and less advanced measurement systems have been made for cross-country skiing, and for roller-skiing as well.

Street and Frederick presented in [6] a measurement system for measuring reaction forces during skate rollerskiing, where one of the roller-skis was equipped with six piezoelectric force sensors; four for measuring the normal forces to the upper surface of the roller-ski and two for measuring the transverse forces at the front and rear wheel. Because no transverse forces were observed during rollerskiing, these sensors were not preloaded in the final design. The ski poles were also equipped with piezoelectric force sensors just below the handle bars for measuring the axial forces. This system was limited by the length of the cables (100 meters), which connected the force sensors and the computer for data storing.

In the study of Bellizzi [7] a similar measuring system is presented. The measuring system has been made from ski poles and roller-skis equipped with strain gauges without any extra pre-processing for amplifying the desired signals and reducing the interfering signals of the force sensors. The roller-skis were supposed to measure the normal reaction forces to the upper surface of the roller-ski and the longitudinal forces of the roller-ski at each wheel. In most similar measuring systems, the latter forces were not measured due to their low values [8] and due to their proportionality with the normal reaction forces. Both, the equipped ski poles and roller-skis raise doubts about the correctness of the measured forces, due to the inappropriate strain gauge application.

Among the newest developed force, measuring systems for skate roller-skiing is the measuring system presented by Hoset et al. [9], where existing roller-skis were equipped with strain gauges to measure the normal reaction forces acting on each wheel. The advantage of this system is that it is wireless and its disadvantage, that it measures only the normal forces.

The aim of the present paper is to:

- present an innovative portable force measuring system developed from processed roller-skis, which measure 
normal and transverse forces at each wheel, and ski poles, which measure axial forces,

present its force sensor calibration,

- present the measurement uncertainty estimation of the entire force sensors' measuring chain, and

- $\quad$ to present exemplar measurement data acquired during roller-ski skating on a treadmill.

\section{METHODS}

A measurement system for measuring the reaction forces during roller-skiing was constructed from processed roller-skis (Alpina 1.1.c., Žiri, Slovenia) and telescopic poles for Nordic skiing (Model 71, Tehnomat 1.1.c., Kranj, Slovenia) instrumented with strain gauge force sensors (Fig. 1). The roller-skis were equipped with four force sensors each, two sensors per each wheel. One sensor measures the reaction forces $F_{3}$ in the normal direction to the upper plane of the roller-skis (sensor S3, direction 3 ) and the other one the reaction forces $F_{2}$ in the axial direction of the wheels (sensor S2, direction 2). The reaction forces $F_{1}$ in the longitudinal direction of the rollerskis (direction 1) are assumed to be proportional to the reaction forces $F_{3}$ [10] and the rolling resistance coefficient $\mu$, which was determined by additional measurements as a function of $F_{3}$ :

$$
\begin{aligned}
& \mu\left(F_{3}\right)=1,161 \times 10^{-10} F_{3}^{3}-1,577 \times 10^{-7} F_{3}^{2}+ \\
& +7,647 \times 10^{-5} F_{3}+6,947 \times 10^{-3}
\end{aligned}
$$

and gives comparable rolling resistance coefficients to coefficients used in other studies [1]. The local coordinate systems of the roller-skis and the defined positive directions of the reaction forces are shown in Fig. 1d. In this figure, also the numbering of the wheels is shown (W1 - W4).

The force sensors of the roller-skis were made from strain gauges connected into full-bridges applied on bending loaded carriers as advised by Hoffmann [11]. For a linear relation between the reaction forces and the output voltage of the full-bridges the original unsymmetrical wheel carriers were replaced by symmetrical rectangular aluminium carriers. The used strain gauges for aluminium alloys (type UFLA - 5-23, Tokyo SokkaKenkuyo Co., Ltd., Japan, gauge factor $k=2,15$ ) have a resistance of $120 \pm$ $0,3 \Omega$. For protection against moisture and mechanical damage the strain gauges were protected with silicone coating and sheet metal guards. The roller-skis are designed for runners up to $85 \mathrm{~kg}$ with shoe sizes up to 44 after the European shoe size system. The bindings for boot connection are from Roteffella (R4 Racing skate, Roteffella, Norway). The mass of one processed roller-skis is $1351 \mathrm{~g}$, the wheelbase is $530 \mathrm{~mm}$.

The force sensors of the poles are located just below the handle bars and measure axial loads in the poles (Fig. 1, a and c). The crucial problem of the pole sensors is to nullify the applied torque influence on the axial load measurement [6]. This problem was solved by the connection between the handle bars and the sensors and by the connection between the sensors and the poles, which do not sustain torque loading around the radial direction of the pole. The pole force sensors roughly consist of an upper and lower sleeve and two symmetric omega shaped profiles between them. The sleeves loosely embrace the poles so they can easily slide along the poles. The axial load transferred from the handles produces a bending torque in the omega shaped profiles proportional to the axial loading. Strain gauges on the omega profiles (type 3/120LY11, HBM, Hottinger Baldwin Messtechnik GmbH, Germany, Darmstadt, $120 \Omega \pm 0,35 \%$, gauge factor $k=2,02$ ) connected into a full-bridge measure this loading as change in the output voltage. Also these strain gauges are protected with silicone coating and protective foam.

The ski pole sensors are dimensioned to the axial force of $300 \mathrm{~N}$, which is the approximate buckling force of the poles. One sensor including the handle bar weighs $158 \mathrm{~g}$, while the whole pole weighs $370 \mathrm{~g}$. The length of the poles can be adjusted from $155 \mathrm{~cm}$ up to $175 \mathrm{~cm}$. The force sensor can also be mounted on other ski poles.

\subsection{Data Acquisition System}

The force sensors on the roller-skis and ski poles were connected with coaxial cables $(75 \Omega / \mathrm{km} \pm 5 \%$ ) to two 24 bit ADC cards (DEWE43, Dewesoft 1.1.c., Trbovlje, Slovenia) placed in the backpack of the athlete. These cards sampled the measured data at $12 \mathrm{kHz}$ and stored it via USB cables on a laptop placed near the treadmill. The ADC cards supplied the force sensors with input voltage of $5 \mathrm{~V} \pm 0,1 \%$. The measuring range of the cards was set to $20 \mathrm{mV} / \mathrm{V}$ for all sensors. The output voltage was filtered by a low-pass Butterworth filter of the second order with a cut-of frequency of $30 \mathrm{~Hz}$. The mass of one ADC card is $720 \mathrm{~g}$.

\subsection{Calibration of the Roller-Ski Sensors}

Calibration of the S3 force sensors was performed on rigidly fixed roller-skies as shown in Fig. 2a. Individual wheel was loaded via a rope in the positive direction 3 by calibration loads of $10 \mathrm{~kg}$ up to a final $40 \mathrm{~kg}$ calibration load. Meanwhile the voltage output signals of both wheel sensors were sampled. In this calibration caution of the calibration force direction was needed, since small angle errors had great influence on the output of the adjacent sensor S2.

While roller-skiing the $F_{2}$ force is applied at the contact point of the wheels and the grounding. This force acts eccentrically to the $\mathrm{S} 2$ sensors and produces additional torque loading around the longitudinal axis of the rollerskis. This was considered in the calibration by usage of a specially developed device (Fig. 2b). This device roughly consists of a vertical linear guide with a clamp for rollerski fixation and two industrial force sensors (PW10AM/300kg, HBM, Hottinger Baldwin Messtechnik GmbH, Darmstadt, Germany, accuracy class C3 according to [12]) through which the calibration load is applied on the wheels. The calibration of both $\mathrm{S} 2$ sensors of a roller-ski was made simultaneously by loading the linear guide with weights in four steps to the maximum weight of 4-5 kg per wheel. The first calibration weight presented the mass of the guide including the clamp and the roller-ski $(3,5 \mathrm{~kg})$. The calibration loads were applied at a radius of $40 \mathrm{~mm}$ (the total wheel radius is $50 \mathrm{~mm}$ ), where the wheel surface is still flat. The $\mathrm{S} 2$ sensors were calibrated in the positive 
(medial) and negative (lateral) direction 2. Also here the output voltages of the calibrated and the adjacent sensor were recorded. The output signal of a calibrated sensor at the $i^{\text {th }}$ wheel due to calibration force in the $j^{\text {th }}$ direction was designated as $U_{j, i}\left(F_{j}\right)$ (useful signal), while the output signal of the adjacent sensor (intended for measuring the forces in the $k^{\text {th }}$ direction) due to the same force was designated as $U_{k, i}\left(F_{j}\right)$ (disturbing signal). The same designations refer to linear approximations of the sensors' output signals.

The direction coefficients of the inverse forms of the useful signals' approximations $\left(\left(U_{j, i}\left(F_{j}\right)\right)^{-1}=F_{j}\left(U_{j, i}\right)\right)$ define the basic conversion factors for transformation of the output voltage signal (volt) to force units (newton).

The disturbing signals of the sensors cause errors to the measurements. To reduce these errors the measured forces were corrected by subtracting the forces measured due to the disturbing signal $F_{j}\left(U_{j, i}\left(F_{k}\right)\right)$. The final conversion

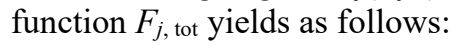

$$
F_{j, \text { tot }}\left(U_{j, i}, F_{k}\right)=F_{j}\left(U_{j, i}\right) \mp F_{j}\left(U_{j, i}\left(F_{k}\right)\right)
$$

In other words, the Eq. (2) can be written as:

$$
F_{j, \text { tot }}\left(U_{j, i}, F_{k}\right)=F_{j}\left(U_{j, i}^{*}\right)
$$

where $U_{j, i}^{*}$ is already the corrected output voltage:

$$
U_{j, i}^{*}=U_{j, i}\left(F_{j}, F_{k}\right) \mp U_{j, i}\left(F_{k}\right)
$$

While running with roller-skies the $F_{2}$ forces are considerably smaller than the $F_{3}$ forces (during a contact phase the average $F_{2} / F_{3}$ ratio has been estimated to less than 0,1$)$. Because of the small influence of the $F_{2}$ forces on S3 sensors (see Fig. 3b) and because of their relatively small values, the disturbing signal on the $\mathrm{S} 3$ sensors due to $F_{2}$ forces was neglected. The final conversion function of the S2 sensors distinguished for the lateral and medial direction of the force $F_{2}$. In the Eqs. (2) and (4) the measured forces/voltages were summed up in the case when the useful and the disturbing forces/voltages were differently signed.

\subsection{Calibration of the Ski Pole Sensors}

While pushing with the poles the force from the hands is transferred to the poles via the handle slings or directly via the handle bar. In both cases, extra torque is applied to the poles [6]. Because the sensor construction nullifies this torque, the calibration of the pole sensors was done centrically on the force sensor by itself as shown in Fig. 2 d. The lower sleeve of the sensor was rigidly fixed, while the upper sleeve was axially loaded by successively adding weights of $1,1,2,3$ and $1 \mathrm{~kg}$ up to the final weight of $8 \mathrm{~kg}$.

\subsection{Measurement Uncertainty of the Measurement System}

The measurement uncertainty of the system was determined in accordance with the guidelines for the expression of uncertainty [12] for each sensor separately. As sources of measurement uncertainty the following sources were accounted: voltage input of the full-bridges $\left(U_{\text {in }}\right)$, resistance of the strain gauges $(R)$, resistance of the electrical wires between the strain gauges and the source voltage $\left(R_{\mathrm{ev}}\right)$, mass of the calibration weights $\left(m_{\text {calib }}\right)$ or reference force $\left(F_{\text {ref }}\right)$, regression model or the final conversion functions $\left(F_{\mathrm{mod}}\right)$ and the voltage of the data acquisition and digitization system $\left(U_{\mathrm{DAQ}}\right)$. The total uncertainty of the first three sources together was determined by the method of "extreme values" after example of Vasuki et al. [13] and represents the uncertainty of the output voltage of the force sensor $\left(U_{\text {out }}\right)$. The total standard uncertainty of the whole measurement system was calculated as:

$u_{\mathrm{c}}(y)=\sqrt{\sum_{i=1}^{N}\left(\frac{\partial f}{\partial x_{i}}\right)^{2} u^{2}\left(x_{i}\right)}$

where the partial derivatives of the measured quantity $f$ by its input quantities' estimates $x_{i}$ (sources of uncertainty) represent sensitivity ratios of input quantities' estimates, $c_{i}$, and $u\left(x_{i}\right)$ standard uncertainties of the input quantities' estimates. All sources of uncertainty were regarded as independent of each other and with rectangular distribution.

The output voltage of a strain gauge, $U_{\text {out }}$, connected into a full bridge on a bending loaded beam considering the resistance of the wires from the voltage supply to the strain gauges $R_{\mathrm{ev}}$, was calculated as [13]:

$U_{\text {out }}=\frac{U_{\mathrm{in}} \cdot \Delta R_{\mathrm{G}}}{R\left(1+\frac{2 \cdot R_{\mathrm{ev}}}{R}\right)}$

The change in resistance of the strain gauges $\Delta R_{\mathrm{G}}$ due to the bending loading was calculated as:

$\Delta R_{\mathrm{G}}=k \cdot \varepsilon \cdot R$

where $k$ is the factor of the strain gauges and $\varepsilon$ their strain. The deviation of the output voltage $\Delta U_{\text {out }}$ of each sensor was calculated using the following equations:

$$
\begin{aligned}
& \left|\Delta U_{\text {out }}\right|=\left|\frac{\partial U_{\text {out }}}{\partial U_{\text {in }}}\right|\left|\Delta U_{\text {in }}\right|+\left|\frac{\partial U_{\text {out }}}{\partial R}\right||\Delta R|+\left|\frac{\partial U_{\text {out }}}{\partial R_{\mathrm{ev}}}\right|\left|\Delta R_{\mathrm{ev}}\right| \\
& \frac{\partial U_{\text {out }}}{\partial U_{\text {in }}}=\frac{\Delta R_{\mathrm{G}}}{R\left(1+\frac{2 \cdot R_{\mathrm{ev}}}{R}\right)} \\
& \frac{\partial U_{\text {out }}}{\partial R}=-\frac{\Delta R_{\mathrm{G}} \cdot U_{\text {in }}}{\left(2 \cdot R_{\mathrm{ev}}+R\right)^{2}} \\
& \frac{\partial U_{\text {out }}}{\partial R_{\mathrm{ev}}}=-\frac{2 \Delta R_{\mathrm{G}} \cdot U_{\text {in }}}{\left(2 \cdot R_{\mathrm{ev}}+R\right)^{2}}
\end{aligned}
$$


where $\Delta U_{\mathrm{in}}, \Delta R$ and $\Delta R_{\mathrm{ev}}$ are maximum spans of quantities $U_{\text {in, }} R$ and $R_{\text {ev }}$ determined by the maximum possible deviations of their nominal values.
All the important assumptions, made in the study, are gathered in Tab. 1.

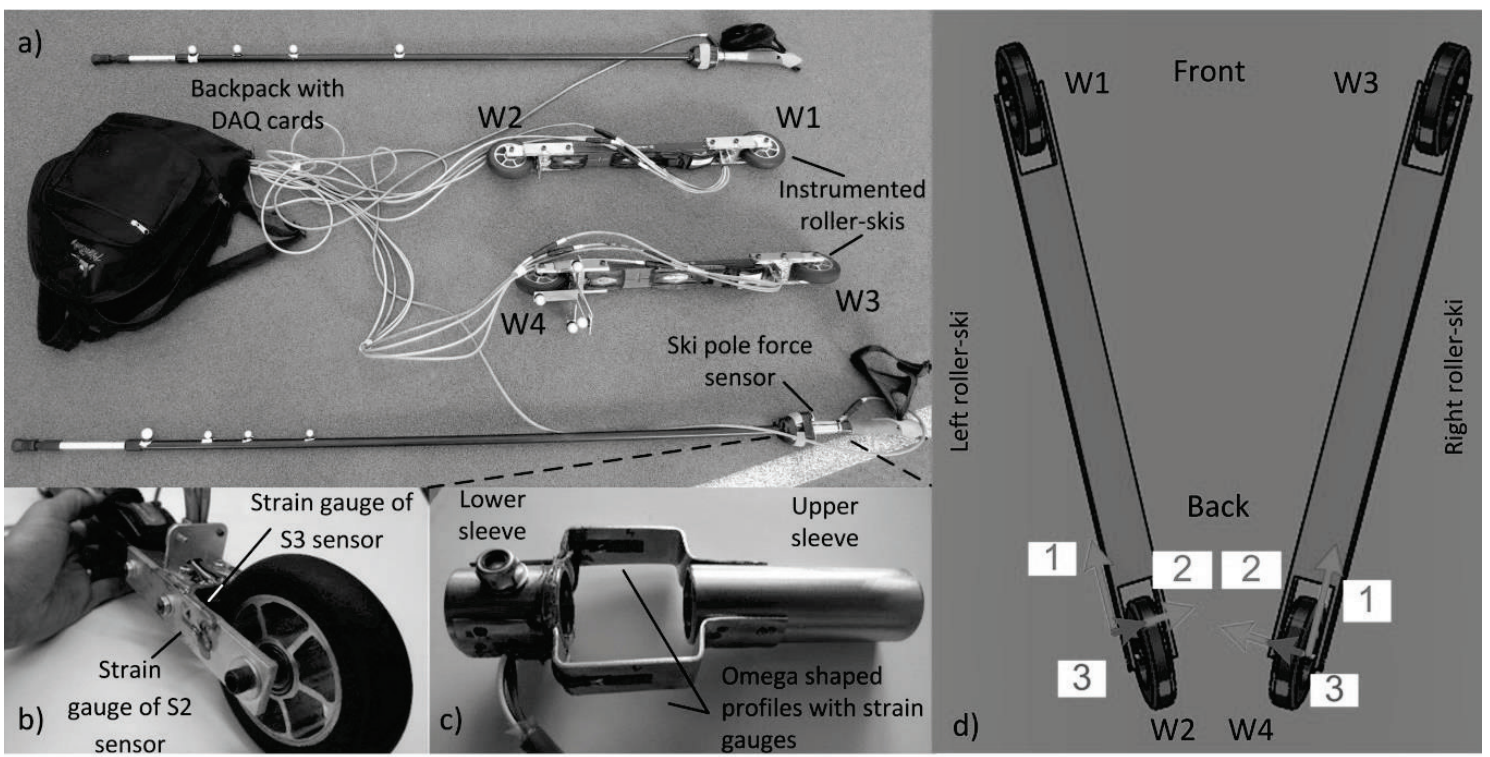

Figure 1 a) The measurement system for measuring reaction forces during roller-skiing, b) zoomed view of the processed roller-ski without sheet metal guards, c) force sensor of a ski pole without protection layers, d) local coordinate systems of the roller-skis and the defined positive directions of the reaction forces.
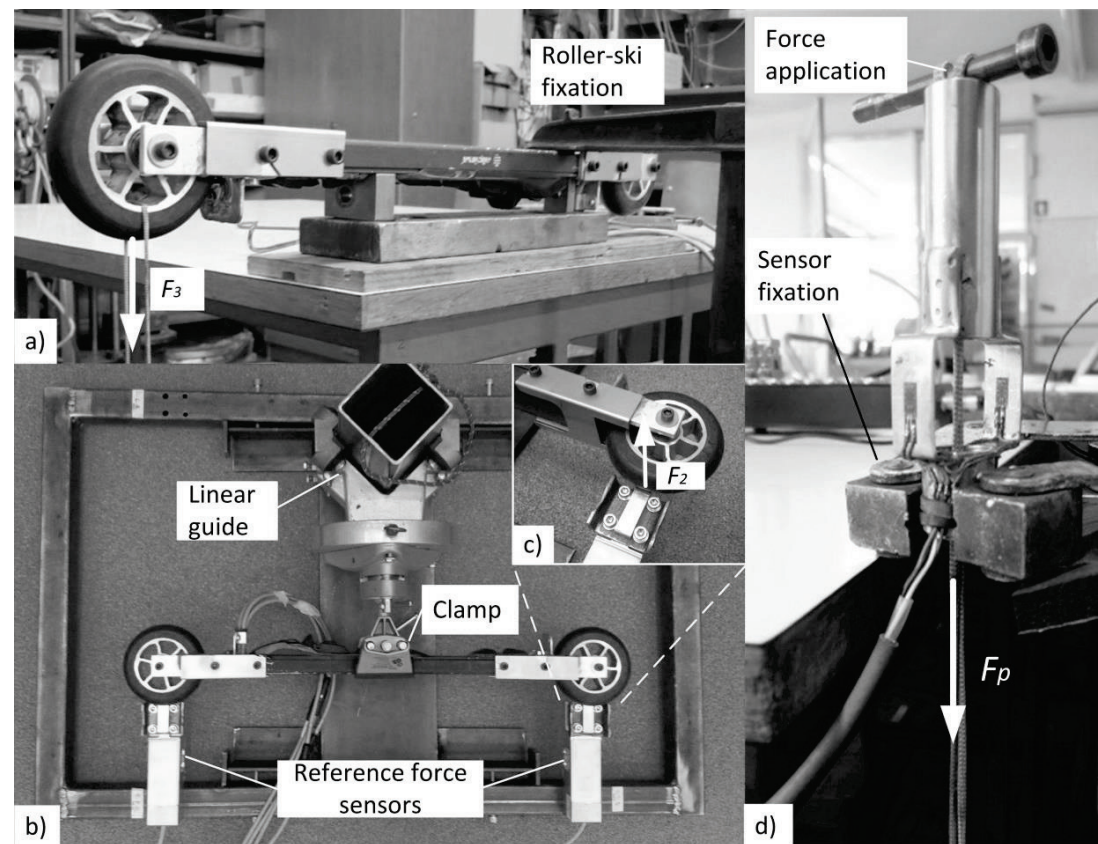

Figure 2 a) Calibration of S3 force sensor, b) calibration of S2 force sensors on a special device made for c) eccentric loading of the wheels. d) Calibration of ski pole force sensor.

Table 1 Table of assumptions

\begin{tabular}{|l|l|}
\hline 1 & The reaction forces $F_{1}$ are proportional to the reaction forces $F_{3}$ and the rolling resistance coefficient $\mu$. \\
\hline 2 & The friction between the handle bars, the pole force sensors and the poles is negligible. \\
\hline 3 & The pole force sensors measure only axial forces. \\
\hline 4 & The strain gauges are rigidly bonded to the bearing material. \\
\hline 5 & The uncertain input parameters have rectangular distribution inside their maximum spans. \\
\hline 6 & The strain gauges connected into a full-bridge have the same resistance and strain. \\
\hline 7 & All the strain gauges of a force sensor are subjected to the same temperature. \\
\hline 8 & Temperature effects on the force sensors are compensated due to the full bridge connection. \\
\hline 9 & The connections within the bridges are short and have therefore negligible effect on the output voltage. \\
\hline 10 & The average $F_{2} / F_{3}$ ratio during skate roller-skiing on a treadmill is less than $0,1$. \\
\hline
\end{tabular}




\section{RESULTS}

For clarity, only calibration results of the S2 and S3 force sensors of wheel W1and both pole force sensors are presented in detail. For other force sensors, just the maximum total measurement uncertainties are reported. In Fig. 3 voltages recorded during calibration of the sensors S2 and S3 are shown. The output voltages of the poles' force sensors in dependence of the calibration forces are shown in Fig. 4. In these figures, also linear approximations and their mean quadratic deviations $\left(R^{2}\right)$ are presented. The worst $\mathrm{R}^{2}$ of all useful signal approximations was 0,9998 for the roller-ski sensors and
0,9999 for the pole sensors, which indicates their significant linear behaviour. In Tab. 2 basic and final conversion functions of wheel W1 sensors are presented.

The intermediate results for the total measurement uncertainty calculations are presented only for the S3 sensor of wheel W1. This sensor turned out to have the maximum relative deviation of the regression model of all the $\mathrm{S} 3$ sensors at a calibration force $F_{3}$ of $195,8 \mathrm{~N}$. In Tab. 3 the data necessary for the calculation of the total measurement uncertainty of its output voltage $U_{\text {out }}$ including sensitivity ratios is presented. From this data the $U_{\text {out }}$ relative standard uncertainty of $0,74 \%$ was calculated.

\begin{tabular}{|c|c|c|c|}
\hline & & Lateral & Medial \\
\hline \multirow{2}{*}{ Basic } & $\mathrm{S} 2$ & $F_{2}\left(U_{2,1}\right)=439,2 \cdot U_{2,1}$ & $F_{2}\left(U_{2,1}\right)=433,5 \cdot U_{2,1}$ \\
\hline & S3 & \multicolumn{2}{|c|}{$F_{3}\left(U_{3,1}\right)=-722,2 \cdot U_{3,1}$} \\
\hline \multirow{2}{*}{ Final } & S2 & $F_{2}\left(U_{2,1}, F_{3}\right)=439,2 \cdot\left(U_{2,1}-2,193 \times 10^{-5} F_{3}\right)$ & $F_{2}\left(U_{2,1}, F_{3}\right)=433,5 \cdot\left(U_{2,1}+2,193 \times 10^{-5} F_{3}\right)$ \\
\hline & S3 & \multicolumn{2}{|c|}{$F_{3}\left(U_{3,1}\right)=-722,2 \cdot U_{3,1}$} \\
\hline
\end{tabular}

a)
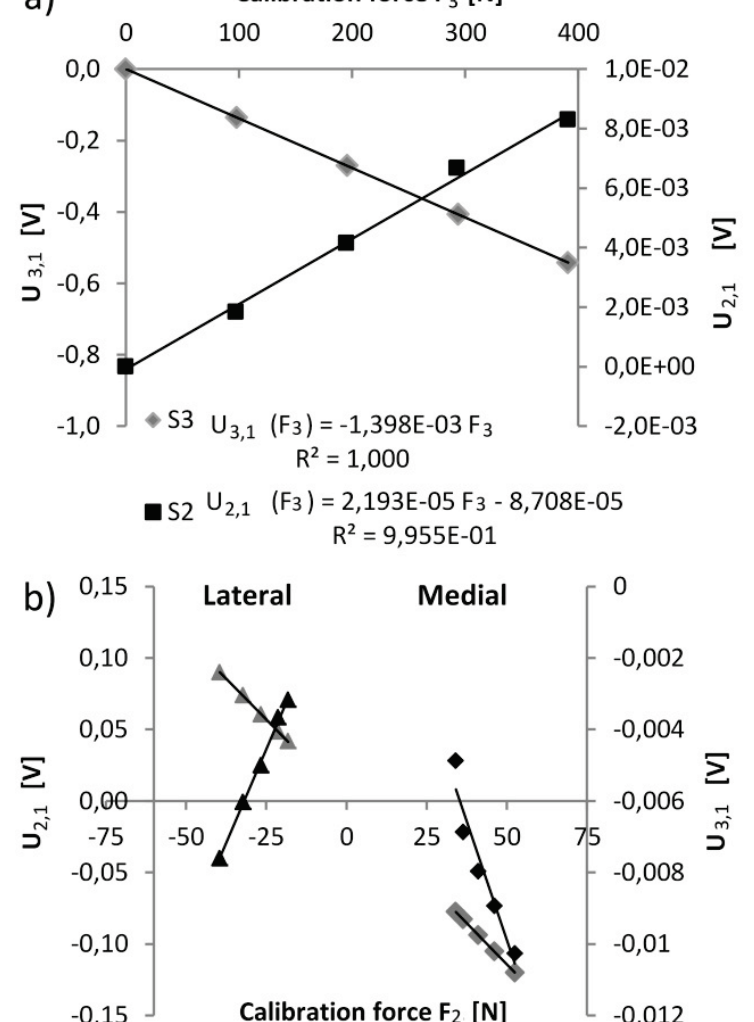

$$
\begin{aligned}
\Delta \text { S2, lateral } \quad U_{2,1}\left(F_{2}\right)= & -2,276 E-03 F_{2}+5,264 E-05 \\
& R^{2}=9,998 E-01
\end{aligned}
$$

Figure 3 Output voltages of sensors S2 and S3 recorded during calibration of roller-ski sensors S3 (a) and S2 (b) of wheel W1, which was calibrated in the lateral and medial direction separately.

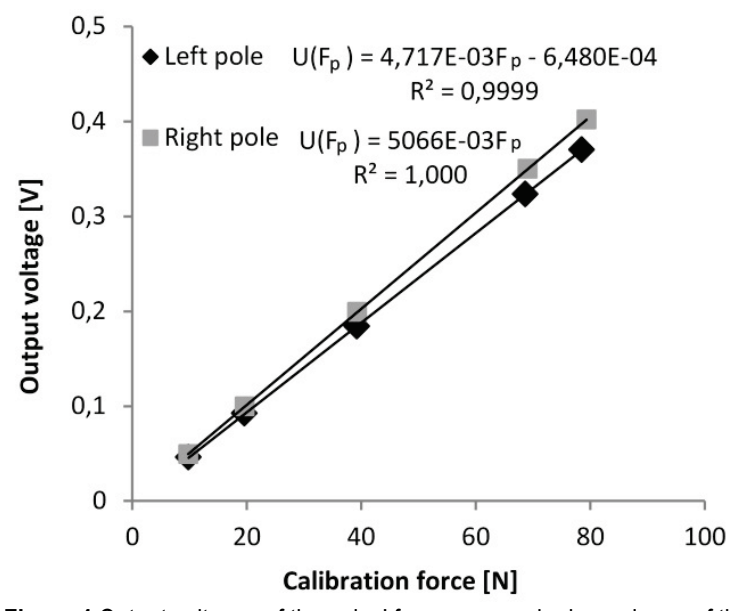

Figure 4 Output voltages of the poles' force sensors in dependence of the calibration force.

Table 3 Necessary data for calculation of the total measurement uncertainty of the output voltage $U_{\text {out }}$ (S3 sensor, wheel W1) including sensitivity ratios at calibration force $F_{3}$, where the maximum relative deviation of the regression model appears.

\begin{tabular}{|c|c|c|c|c|}
\hline $\begin{array}{c}\text { Source of } \\
\text { measurement } \\
\text { uncertainty }\end{array}$ & $\begin{array}{c}\text { Nominal } \\
\text { value }\end{array}$ & $\begin{array}{c}\text { Tolerance } \\
\text { of the } \\
\text { nominal } \\
\text { value }\end{array}$ & $\begin{array}{c}\text { Maximum } \\
\text { span }\end{array}$ & $\begin{array}{c}\text { Sensitivity } \\
\text { ratio } c_{i}\end{array}$ \\
\hline$U_{\text {in }}$ & $5 \mathrm{~V}$ & $\pm 0,1 \%$ & $0,01 \mathrm{~V}$ & $2,789 \mathrm{E}-04$ \\
\hline$R$ & $120 \Omega$ & $\pm 0,3 \Omega$ & $0,6 \Omega$ & $-1,158 \mathrm{E}-05$ \\
\hline$R_{\mathrm{ev}}$ & $0,225 \Omega$ & $\pm 0,01125 \Omega$ & $0,0225 \Omega$ & $-2,315 \mathrm{E}-05$ \\
\hline
\end{tabular}

Table 4 Necessary data for calculation of the total measurement uncertainty of the complete measuring chain ( 33 sensor, wheel W1) at calibration force $F_{3}$, where the maximum relative deviation of the regression model appears.

\begin{tabular}{|c|c|c|c|}
\hline $\begin{array}{c}\text { Source of } \\
\text { measurement } \\
\text { uncertainty }\end{array}$ & $\begin{array}{c}\text { Nominal } \\
\text { value }\end{array}$ & $\begin{array}{c}\text { Tolerance of } \\
\text { the nominal } \\
\text { value }\end{array}$ & $\begin{array}{c}\text { Standard } \\
\text { uncertainty } \\
(\mathrm{V})\end{array}$ \\
\hline$U_{\text {out }}$ & $1,394 \mathrm{E}-03 \mathrm{~V}$ & $\pm 0,74 \%$ & $5,921 \mathrm{E}-06$ \\
\hline m $_{\text {calib }}$ & $20 \mathrm{~kg}$ & $\pm 2 \times 0,5 \mathrm{~g} *$ & $7,842 \mathrm{E}-06$ \\
\hline$U_{\text {DAQ }}$ & $0,2702 \mathrm{~V}$ & $\begin{array}{c}0,05 \% U_{\mathrm{DAQ}} \\
\pm 0,1 \mathrm{mV}\end{array}$ & $1,357 \mathrm{E}-04$ \\
\hline$F_{\text {mod }}$ & $195,2 \mathrm{~N}$ & $\pm 1,56 \% F_{3}$ & $2,433 \mathrm{E}-03$ \\
\hline *Two calibration weights of $20,00 \mathrm{~kg}$ were used
\end{tabular}

In Tab. 4 the data necessary for calculation of the total measurement uncertainty of the complete measuring chain 
at the maximum regression model deviation are presented. The relative standard total measurement uncertainty at this point turned out to be $\pm 0,90 \%$ of $F_{3}$ and the relative total measurement uncertainty with a $95 \%$ confidence level turned out to be $\pm 1,80 \%$ of $F_{3}$. These two values expressed regarding the maximum calibration force $F_{3}$ yield $0,45 \%$ and $0,90 \%$.

The maximum measurement uncertainty of the entire measuring chain of the S2 sensors at a confidence level of $95 \%$ was $\pm 2,34 \%$ of the maximum calibration force $F_{2}$. For the pole force sensors this maximum measurement uncertainty made up to $\pm 1,47 \%$ of the maximum calibration force.

In Fig. 5 exemplar measurement data of one typical cycle during skate roller-skiing on a treadmill are presented. The used skating technique was G3 (each roller- ski push-off is followed by a symmetrical pole push-off), the treadmills speed was $10 \mathrm{~km} / \mathrm{h}$ and its inclination was $5 \%$. As expected forces $F_{3}$ represent the maximal forces with maximums up to approximately $130 \%$ of the runner's body weight due to dynamic effects. The course of the $F_{3}$ forces' contact phase has two distinct summits. The first summit is due to the takeover of the runner's weight when landing on the roller-ski. This summit is followed by a depression due to the movement of the runner's centre of gravity (COG) towards the roller-ski. The force $F_{3}$ begins to rise again, when the acceleration of the COG changes its sign in direction 3 , till it reaches the second maximum. At this point also the acceleration of COG reaches its maximum and the roller-ski begins to take-off. Consequentially $F_{3}$ drops.
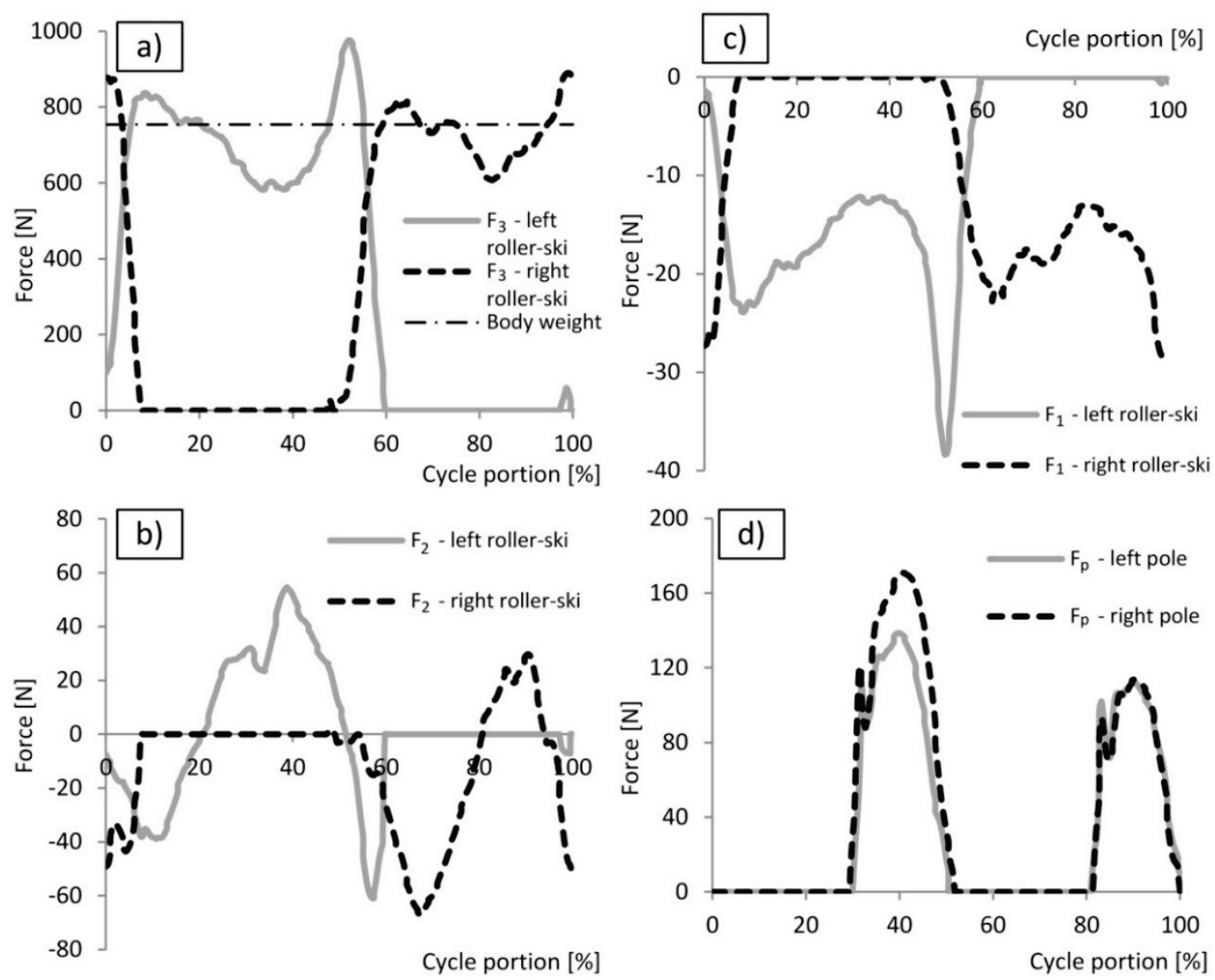

Figure 5 Measured reaction forces during roller-skiing of one typical cycle: a) $F_{3}$ reaction forces, b) $F_{2}$ reaction forces and c) calculated $F_{1}$ reaction forces of the rollerskis. d) Reaction forces of the ski poles.

Forces $F_{2}$ have much lower values than $F_{3}$ forces; maximums are about $10 \%$ of the runners' body weight. Their course varies from cycle to cycle more than the course of $F_{3}$ forces. Typically the $F_{2}$ force changes its sign twice per contact phase: when taking over the runners' weight, the $F_{2}$ force is negative, when the $F_{3}$ force depresses, the $F_{2}$ force goes positive, and when the $F_{3}$ force begins to rise again, the $F_{2}$ force goes negative again. This last negative part of $F_{2}$ force happens in the push-off phase. Its occurrence is suspected due to the transfer of the $F_{3}$ push-off force from the lateral side of the foot to the medial side.

Forces $F_{1}$ occur due to the rolling resistance of the roller-skis. These forces were calculated after Eq. (1). Their maximum values are approximately $5 \%$ of the runners' body weight.
The axial forces in the poles have a typical parabolic course with a small sharp peak at the beginning. This peak is expected to be a consequence of the deformation of the rubber nozzles, used for treadmill running, attached to the tips of the poles. Maximum values of pole forces are approximately $20 \%$ of the runner's body weight.

\section{DISCUSSION AND CONCLUSION}

An advanced force measurement system for rollerskiing was presented, which in comparison to other existing measurement systems $[6,7,9]$ also measures the transverse reaction forces in the axial wheel directions. The force sensors of the poles present an elegant solution to nullify the influence of the torque and to amplify the influence of the axial load on the force sensors' output. 
These sensors can also be mounted onto other poles with few modifications.

Measurement uncertainty estimates of the force sensors were calculated at a confidence level of $95 \%$. For one force sensor the calculation was shown more in detail. The maximal measurement uncertainties of the sensors were up to $\pm 2,34 \%$ of the maximum calibration forces. These uncertainty estimates, based on the worst case scenarios, are comparable to the accuracies of the most precise roller-ski measuring systems [6].

Exemplar measures of the reaction forces during treadmill roller-skiing were presented and interpreted. This data is important for understanding the biomechanics of skate roller-skiing. In contrast to the study of Street and Frederick [6] the recorded $F_{2}$ force of the roller-skis was found not to be negligible, since their maximums' size presents approximately $10 \%$ of the runner's body weight. The presented measurement system is also appropriate for terrain usage. In this case the athlete also needs to carry a laptop in his backpack and a battery for supplying the data acquisition (DAQ) cards. For future work, it is recommended to reduce the weight of the measurement system, which can be accomplished by processing lighter skis and poles. Elimination of wire connections between the sensors and ADC cards would also significantly contribute to the applicability of the measuring system.

\section{REFERENCES}

[1] Herrmann, H. \& Clauß, M. (1998). Biomechanical analysis of the dynamics of skating. Proceedings of the XVI International Symposium on Biomechanics in Sports, 16 International Symposium on Biomechanics in Sports / Konstanz, Germany, 182-185.

[2] Pohjola, M. (2014). Analysing effectiveness of force application in ski skating using force and motion capture data - a model to support cross-country skiing research and coaching. Master thesis, Department of Biology of Sport, University of Jyväskylä.

[3] Stoggl, T., Muller, E., Ainegren, M., \& Holmberg, H. C. (2011). General strength and kinetics: Fundamental to sprinting faster in cross-country skiing? Scand J Med SciSpor, 21(6), 791-803. https://doi.org/10.1111/j.1600-0838.2009.01078.x

[4] Holmberg, H. C., Lindinger, S., Stoggl, T., Eitzlmair, E., \& Muller, E. (2005). Biomechanical analysis of double poling in elite cross-country skiers. Med Sci Sport Exer, 37(5), 807818. https://doi.org/10.1249/01.MSS.0000162615.47763.C8

[5] Pellegrini, B., Zoppirolli, C., Bortolan, L., Zamparo, P., \& Schena, F. (2014). Gait models and mechanical energy in three cross-country skiing techniques. J ExpBiol, 217(21), 3910-3918. https://doi.org/10.1242/jeb.106740

[6] Street, G. M. \& Frederick, E. C. (1995). Measurement of skier-generated forces during roller-ski skating. $J$ ApplBiomech, 11(3), 245-256. https://doi.org/10.1123/jab.11.3.245

[7] Bellizzi, M. J., King, M. A. D., Cushman, S. K., \& Weyand, P. G. (1998). Does the application of ground force set the energetic cost of cross-country skiing? J ApplPhysiol, 85(5), 1736-1743. https://doi.org/10.1152/jappl.1998.85.5.1736

[8] Baumann, W. (1985). The mechanics of the roller ski and its influence on technique in cross-country skiing. $J$ Biomech, 18(7), 551-552. https://doi.org/10.1016/0021-9290(85)90820-6

[9] Hoset, M., Rognstad, A. B., Rølvåg, T., Ettema, G., \& Sandbakk, Ø. (2013). Construction of an instrumented roller ski and validation of three-dimensional forces in the skating technique. Sports Engineering, 17(1), 23-32. https://doi.org/10.1007/s12283-013-0130-2

[10] Ainegren, M. (2012). Roller-skis' rolling resistance and grip characteristics - influences on physiological and performance measures in cross-country skiers. Doctoral thesis, Department of Engineering and Sustainable Development, Mid Sweden University, Östersund.

[11] Hoffmann, K. (2001). Applying the Wheatstone bridge circuit, HBM.

[13] JCGM. (2008). Evaluation of measurement data - guide to the expression of uncertainty in measurement. International Organization for Standardization, Geneva, Switzerland.

[14] Vasuki, B., Umapathy, M., \& Senthilkumarr, A. R. (2009). Uncertainty analysis of strain gage circuits: Interval method and interval algorithm. International journal on smart sensing and intelligent systems, 2(3), 477-489. https://doi.org/10.21307/ijssis-2017-362

\section{List of abbreviations \\ Notation \\ ADC analog to digital converter \\ COG centre of gravity \\ DAQ data acquisition}

\begin{tabular}{|c|c|}
\hline \multicolumn{2}{|c|}{ List of symbols } \\
\hline$c_{i}$ & sensitivity ratios of input quantities' estimates \\
\hline$f$ & measured quantity \\
\hline$F_{j \text {, tot }}$ & final conversion function \\
\hline$F_{\text {mod }}$ & regression model of the measured force \\
\hline$F_{\text {ref }}$ & reference calibration force \\
\hline$F_{1}$ & $\begin{array}{l}\text { reaction forces in the longitudinal direction of the } \\
\text { roller-skis }\end{array}$ \\
\hline$F_{2}$ & reaction forces in the axial direction of the wheels \\
\hline$F_{3}$ & $\begin{array}{l}\text { reaction forces in the normal direction to the upper } \\
\text { plane of the roller-skis }\end{array}$ \\
\hline$k$ & factor of strain gauges \\
\hline$m_{\text {calib }}$ & mass of the calibration weights \\
\hline$R$ & resistance of the strain gauges \\
\hline$R_{\mathrm{ev}}$ & resistance of the electrical wires \\
\hline$R_{\mathrm{G}}$ & resistance of the strain gauges \\
\hline$R^{2}$ & mean quadratic deviation \\
\hline$u_{\mathrm{c}}(y)$ & total standard uncertainty \\
\hline$u$ & standard uncertainty \\
\hline$U_{\mathrm{DAQ}}$ & voltage of data acquisition and digitization system \\
\hline$U_{\text {in }}$ & voltage input of the full-bridges \\
\hline$U_{j, i}\left(F_{j}\right)$ & $\begin{array}{l}\text { useful signal at the } i^{\text {th }} \text { wheel sensor due to } \\
\text { calibration force in the } j^{\text {th }} \text { direction }\end{array}$ \\
\hline$U_{j, i}^{*}$ & corrected output voltage \\
\hline$U_{k, i}\left(F_{j}\right)$ & $\begin{array}{l}\text { disturbing signal at the } i^{\text {th }} \text { wheel sensor due to force } \\
\text { in the } j^{\text {th }} \text { direction }\end{array}$ \\
\hline$U_{\text {out }}$ & output voltage of the force sensor \\
\hline$x_{i}$ & estimates of sources of uncertainty \\
\hline$\varepsilon$ & strain \\
\hline$\mu$ & rolling resistance coefficient \\
\hline
\end{tabular}

\section{Contact information:}

Jurij HLADNIK, Assist. BCs

Faculty of Mechanical Engineering, University of Ljubljana

Aškerčeva 6, 1000 Ljubljana, Slovenia

jurij.hladnik@fs.uni-lj.si

Matej SUPEJ, Assoc. Prof. PhD

Faculty of Sport, University of Ljubljana

Gortanova ul. 22, 1000 Ljubljana, Slovenia

matej.supej@fsp.uni-lj.si

Boris JERMAN, Assist. Prof. PhD

Faculty of Mechanical Engineering, University of Ljubljana,

Aškerčeva 6, 1000 Ljubljana, Slovenia

boris.jerman@fs.uni-lj.si 